\title{
Uma espécie nova de Epirhyssa Cresson (Ichneumonidae, Hymenoptera) do Brasil ${ }^{1}$
}

\author{
A new species of \\ Epirhyssa Cresson, 1865 (Ichneumonidae, \\ Hymenoptera) from Brazil ${ }^{1}$
}

\section{VinALTO GRAF ${ }^{2}$ \\ Alice Fumi KumagaI ${ }^{3}$}

Os Epirhyssa são ichneumonídeos grandes, típicos de florestas tropicais. PORTER (1978) na revisão do gênero estudou 38 espécies da Região Neotropical, das quais 25 novas e 16 ocorrem no Brasil; estes parasitóides são em geral raros nas coleções: "Most species of Epirhyssa are uncommon and often only two or three specimens will be obtained in several months of exhaustive daily collecting" (Porter, 1978).GAuld (1991) apresenta dez espécies de Epirhysssa para Costa Rica, uma não descrita para Austrália e coloca em sinonimia de Epyrhyssa Cresson, 1865 Sychnostigma Baltazar, 1961, dos trópicos do velho mundo (GAULD, 1984). O catálogo dos ichneumonídeos de Yu \& Horstmann (1997) tem 44 espécies de Epirhyssa para a Região Neotropical. O espécime estudado está na Coleção de Entomologia Pe. J. S. Moure, Departamento de Zoologia da Universidade Federal do Paraná, Curitiba (DZUP).

\footnotetext{
${ }^{1}$ Contribuição 1509 do Departamento de Zoologia, Universidade Federal do Paraná. 2 -Departamento de Zoologia, UFPR, Caixa Postal 19020 - 81531-980 Curitiba, Paraná, Brasil. vig @.ufpr.br. ${ }^{3}$ Departamento de Zoologia, UFMG, Caixa Postal 486 - 31270-901, Belo Horizonte, Minas Gerais, Brasil. acfk@mono.icb.ufmg.br
} 


\section{Epirhyssa nigrithorax sp. nov.}

(Figs 1-5)

Diagnose - Carena occipital fraca, bem separada da hipostomal; quase todo o mesosoma, coxas médias e posteriores, parte apical do metasoma e partes da cabeça, pretos brilhantes.

\section{HoLÓTIPO FÊMEA}

Face enegrecida, com mancha amarela logo abaixo dos alvéolos antenais; órbitas anteriores, das fóveas tentoriais até pouco acima dos alvéolos antenais, amareladas; genas e clípeo amarelos exceto partes negras das genas junto aos olhos e do occipício; fronte, desde os alvéolos antenais, vértice, occipício e pós-occipício incluindo toda área ocelar, pretos; antenas marrom-enegrecidas, escapo com a margem apical amarelada; mandíbulas fulvas na sua metade basal, metade distal preta. Colar do pronoto e propleura amarelos com manchas enegrecidas. Escutelo amarelado com mancha preta triangular na sua metade distal. Asas tingidas de amarelo-claro menos a parte distal, marrom-enegrecida desde a metade da célula marginal; sem faixa transversal preta, pterostigma amarelo vivo. Pernas amarelo-fulvas, as coxas médias e posteriores pretas, brilhantes; os distitarsos anteriores e os dois tarsômeros distais das pernas médias pretos; os tarsos posteriores enegrecidos, os distais mais escuros. Os tergos 1-4 e o terço basal do 5 fulvos, os dois terços distais do tergo 5 e do 6 a 9 pretos.

Face convexa no meio, com pontos finos, esparsos, as cerdas longas e eretas; fronte, vértice e occipício lisos, brilhantes, com pontos muito finos e esparsos; clípeo um pouco dilatado nos lados, a margem apical côncava com tubérculo vestigial no meio; carena occipital fraca na parte lateral, ausente no meio do vértice e na metade inferior da gena. Lobo médio do mesoscuto não projetado sobre o pronoto; carena pré-pectal bem definida no mesosterno, alcança a metade da distância à área subalar; carena submetapleural fraca, quase imperceptível no meio. Propódeo liso, polido, com pontos finos e pêlos eretos, 


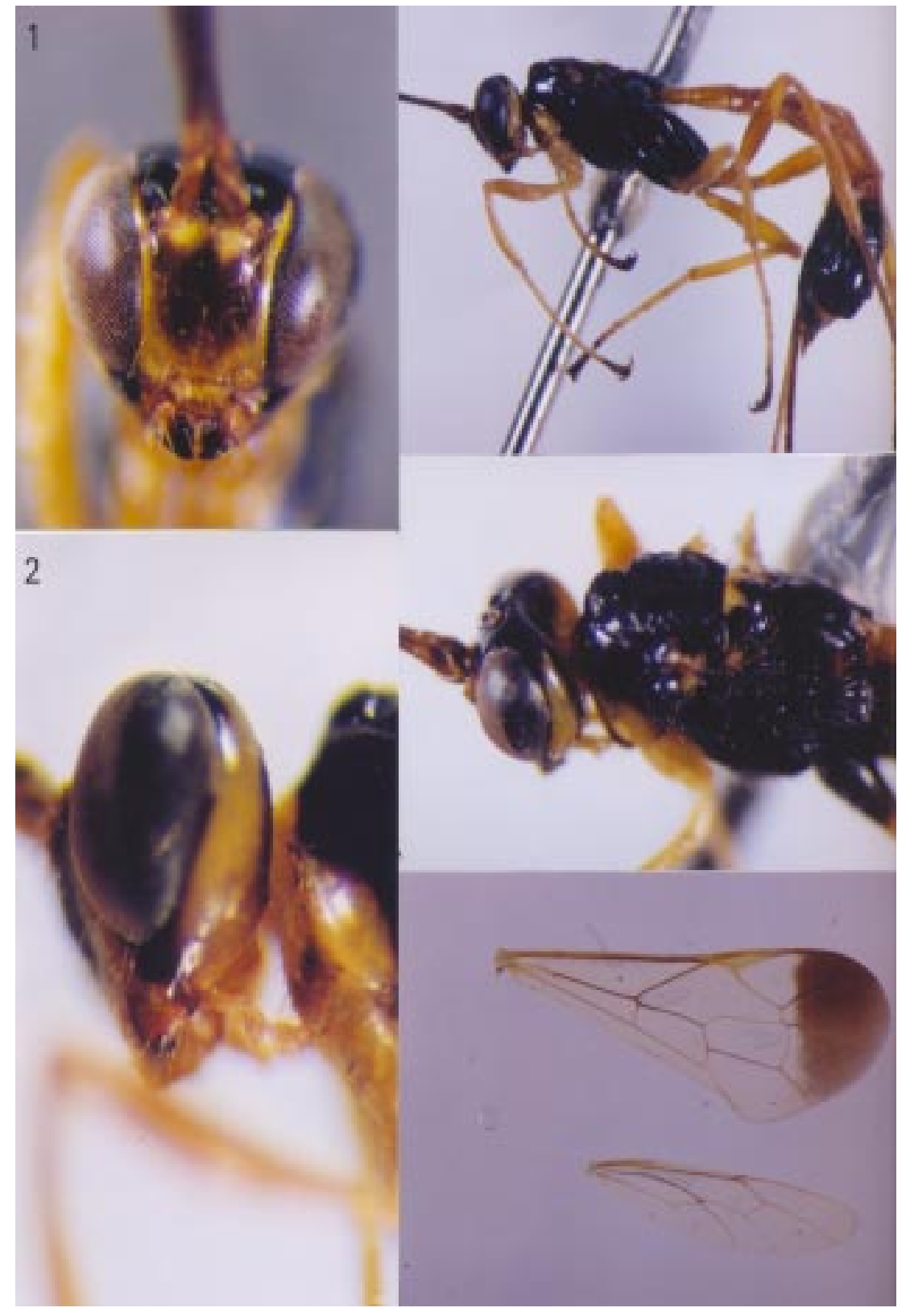

Figs 1 a 5. Epirhyssa nigrithorax sp. nov. 1, cabeça em vista anterior; 2, cabeça em vista lateral; 3, corpo em vista dorso-lateral; 4 , asas. 
longos e esparsos, abaixo do espiráculo; depressão mediana fraca, da base até um pouco mais da metade do comprimento do propódeo.

Tergo basal tão longo como duas vezes sua largura apical, com carena látero-dorsal fraca, perceptível até o espiráculo, pêlos longos, eretos e esparsos, ao longo das margens laterais; tergo 2 liso e polido com estrias muito finas, longitudinais e irregulares na sua metade basal.

Largura da cabeça 1,28 mm; altura da cabeça $0,96 \mathrm{~mm}$; distância interorbital superior $0,66 \mathrm{~mm}$; distância interorbital inferior $0,54 \mathrm{~mm}$; comprimento da tíbia posterior $2,17 \mathrm{~mm}$; comprimento do ovipositor $9,50 \mathrm{~mm}$; comprimento das antenas 7,50 $\mathrm{mm}$; comprimento da asa anterior $6,67 \mathrm{~mm}$ (as asas estão coladas em duas etiquetas, no alfinete do holótipo).

Holótipo fÊMeA - BRASIL, Rondônia, Vilhena, 22/X/86, C. Elias leg. Polonoroeste, depositado no DZUP.

Etimologia - O nome específico é alusivo à cor preta do mesosoma.

\section{DisCUSSÃO}

Epirhyssa nigrithorax sp. nov. é semelhante às espécies $E$. leuceres Porter, 1978 do Pará, Brasil e E. melampyge Porter, 1978 de Cuzco, Perú que têm em comum a carena occipital incompleta, reduzida, separada da carena hipostomal; flagelo antenal marrom-enegrecido sem anel esbranquiçado. As asas anteriores de E. leuceres têm larga faixa transversal basal ao pterostigma marrom-escura; E. melampyge tem o mesosoma fulvo e amarelo, metasoma fulvo com os tergos apicais 6 a 9 escuros, asas anteriores hialinas com mancha enegrecida no ápice e pernas fulvas com as coxas amarelas. E. nigrithorax tem o mesosoma e os tergos distais 6 a 9 e parte distal do tergo 5, negros; asas anteriores lavadas de amarelo-claro e mancha apical escura; pernas médias e posteriores com as coxas pretas.

Agradecimentos — Os autores agradecem à Profa. Danúncia Urban pela revisão do texto e ao Prof. Albino M. Sakakibara pela feitura das fotografias. 


\section{RESUMO}

É descrita uma espécie nova de Epirhyssa Porter, 1978, E. nigrithorax sp. nov., de Vilhena, Rondônia, BRASIL, com carena occipital reduzida, o mesosoma, as coxas médias e posteriores e os tergos distais, pretos.

Palavras chave: Epirhyssa, Ichneumonidae, Hymenoptera, espécie-nova.

\section{SUMMARY}

Epirhyssa nigrithorax sp. n. from Vilhena, RONDÔNIA, BRAZIL is described; it has mesosoma, coxae of the mid and posterior legs and the distal tergites black.

KeY Words: Epirhyssa, Ichneumonidae, Hymenoptera, new-species, Brazil

\section{RÉSUMÉ}

Epirhyssa nigrithorax sp. nov. est décrit du BRÉSIL (Vilhena, RONDÔNIA); en la espèce nouvelle, la carène occipital est vestigial; sont noires le mesosoma, sommet du metasoma et les coxas moyenne et postérieur.

Mots CLÉs: Epirhyssa, Ichneumonidae, Hymenoptera, espèce nouvelle, Brésil.

\section{BIBLIOGRAFIA}

GaulD, I. D. 1984. An Introduction to the Ichneumonidae of Australia. British Museum, Natural History, 413 pp.

Gauld, I. D 1991. The Ichneumonidae of Costa Rica, 1. Memoirs of the American Entomological Institute, 47: 1-589.

PORTER, C. C. 1978. A Revision of the Genus Epirhyssa (Hymenoptera, Ichneumonidae). Studia Entomol. 20 (1-4): 297-412.

Yu, D. S. \& K. Horstmann. 1997. A Catalogue of World Ichneumonidae (Hymenoptera). Memoirs of the American Entomological Institute, 58, $1556 \mathrm{pp}$.

Recebido em: 2.06.2003 